\title{
4 \\ APLICAÇÃO REAL DO MODELO PROPOSTO: \\ O CASO SIBER DO BRASIL S.A.
}

O propósito desta seção é descrever a aplicação do modelo híbrido proposto de SCM baseado na TOC-VMI-B2B, implementado na Siber do Brasil S.A., o qual integra a empresa com todos os seus parceiros e clientes na cadeia de suprimentos, através do compartilhamento de informações entre os ERPs, propiciando a este modelo operar como um sistema de planejamento e programação avançados (advanced planning and scheduling - APS), resultando em um eficiente SCM voltado para as necessidades do mercado.

\subsection{DESCRIÇÃO DA EMPRESA E CENÁRIO}

A Siber do Brasil S.A. é uma empresa multinacional italiana de médio porte, voltada para o mercado de componentes eletro-mecânicos e eletrônicos voltados para a manufatura de produtos para linhas de eletrodomésticos. Possui duas plantas no Brasil, localizadas em São José dos Campos e Guararema, no estado de São Paulo.

Característica de mercado, manufatura e produto (SANTOS, 2005):

- Grandes volumes de produção: 45.000 produtos por dia;

- Componentes montados em dois ou três níveis em sua árvore-deproduto;

- Tipos de produtos: interruptores ligados a cabos elétricos e componentes eletrônicos, resistências a quartz para o processo de douração em fornos de micro-ondas e fogões convencionais, dentre outros;

- Linha de produção com montagem de um mix aproximado de 300 produtos, cada um deles composto de 10 a 15 componentes diferentes;

- Total de 800 tipos de diferentes componentes no estoque. 
Conforme discorrido no capítulo 2.1 deste trabalho, o diferencial competitivo de uma empresa se concentra hoje na excelência da gestão envolvendo logística, armazenagem e abastecimento, alinhada à estratégia de aquisição e gestão do seu processo de manufatura.

Devido ao ambiente cada vez mais competitivo e globalizado, a concorrência tem migrado das empresas para o SCM. Deste modo, o gerenciamento limitado ao conhecimento técnico e à manufatura dos produtos é condição necessária, mas não suficiente, para o sucesso empresarial, devendo ser estimulada a pesquisa por estratégias administrativas capazes de promover um serviço de excelência aos clientes.

É neste contexto que a Siber do Brasil se encaixa. No final da década de noventa, mesmo com uma vasta propriedade sobre o domínio tecnológico peculiar em seu ramo, aliado a uma forte experiência em seu seguimento de mercado, a companhia necessitava redirecionar suas estratégias empresariais de gestão, pois a busca pela perpetuidade da empresa frente ao cenário competitivo levou seus dirigentes a romperem definitivamente com os paradigmas empresariais existentes, para então implementarem novas estratégias que viabilizassem o redirecionamento da empresa em direção ao mercado e ao lucro.

O cenário no qual a empresa se encontrava pode ser resumidamente descrito, conforme segue:

- Dificuldades financeiras;

- Flexibilidade de produção depreciada;

- Lead-time de entrega de até 6 semanas, levando os clientes a frequentes interrupções e mudanças de programação de produção;

- Altos níveis de inventário, com estoques acumulados para uma demanda de até 5 meses, porém sem garantia de todos os componentes necessários para montar os produtos demandados pelos clientes;

- Consequentes dificuldades financeiras, em função de capital-de-giro "empatado" nos estoques e postergação das receitas devido aos atrasos nas entregas.

Para a mudança deste cenário, um dos problemas-raiz diagnosticados foi a predominância e o uso de informações dispersas e desatualizadas acerca de:

- Estrutura de produtos;

- Capacidade de produção das células de manufatura; 
- Controle de materiais e estoques (quantidades, empenhos de ordens de produção e materiais em processo);

- Cruzamento dos estoques com o planejamento de suprimentos;

- Capacidade de produção e entrega dos fornecedores, e acuracidade de seus respectivos lotes econômicos de compras.

Além disto, é importante destacar mais duas questões:

- A disconexão destas informações com a realidade dos planos de produção para se atender o mercado;

- A extensão deste mesmos problemas para todos os outros parceiros da cadeia de suprimentos, em que o sistema "empurrado" contribuía também para a amplificação da demanda (efeito chicote).

De fato, o sistema de TI utilizado pela empresa não estava satisfazendo as expectativas dos gerentes, justamente pelos dados fornecidos para tomadas de decisão estarem incompletos ou incongruentes com a realidade e, como consequência, os acionistas demandaram uma mudança de curso imediata na estratégia da empresa, a fim de manter os investimentos da companhia.

Uma das primeiras mudanças adotadas foi a substituição do atual sistema de gerenciamento de TI por um novo software denominado Customer Integrated System - CIS (a ser detalhado na próxima seção).

Naquela ocasião, enquanto a completa implementação do CIS não era estabelecida, o gerenciamento era parcialmente baseado na TOC, com a aplicação dos conceitos da programação TPC na manufatura interna.

Porém, este novo método não foi suficientemente capaz de resolver todos os problemas de gestão, posto que em um SCM todos os parceiros devem trabalhar como uma entidade homogênea. Este cenário mudou positivamente quando finalmente o CIS foi estabelecido na sua totalidade, incluindo um modo logístico inovador com as ferramentas VMI e B2B, soluções estas que propiciaram a comunicação "em tempo real" junto às outras empresas, com o compartilhamento das informações empresariais entre todas as companhias, operando então como um sistema APS. 


\subsection{O SISTEMA DE ERP CUSTOMER INTEGRATED SYSTEM}

\section{(CIS ${ }^{11}$ )}

O CIS é um sistema ERP baseado nos conceitos da TOC operando de forma híbrida com diversas ferramentas de gestão e, desta forma, integrando todas as áreas da empresa, sempre gerenciando com o foco nas necessidades do cliente, razão esta que determinará o direcionamento de todas as informações e decisões.

A sua operação é supervisionada pelo departamento comercial, a fim de garantir a constante convergência do processo de planejamento ao encontro das demandas dos clientes, propiciando este alinhamento durante todas as interfaces das operações, abrangendo a produção, suprimentos, estoques e demais áreas da companhia.

A Figura 30 ilustra como o CIS envolve todos os departamentos da Siber do Brasil S.A., a fim de obter o completo atendimento às necessidades dos clientes externos, posicionados estrategicamente no centro das decisões.

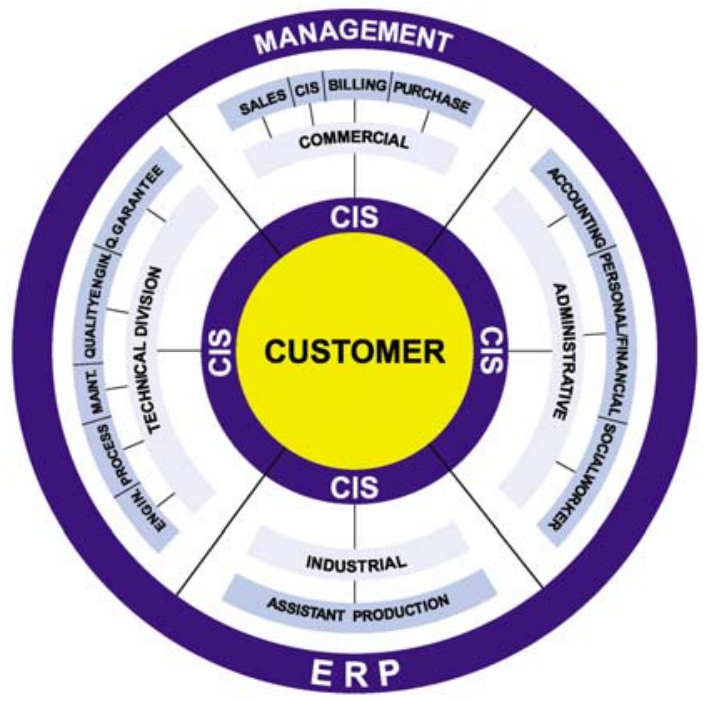

Figura 30 - Gestão da Siber do Brasil S.A. com foco no cliente, através do CIS.

(www.cis-erp. com.br, 2007)

O algoritmo do módulo logístico do CIS é apoiado na TOC, especificamente utilizando o modelo TPC e o gerenciamento dos pulmões para a manufatura e

\footnotetext{
${ }^{11}$ www.cis-erp. com.br, 2007.
} 
processos de suprimentos sincronizados, com o propósito de controlar o relacionamento entre os clientes e fornecedores da empresa.

\subsection{A INTEGRAÇÃO CIS \& TOC-VMI-B2B NA SIBER DO BRASIL}

Nesta seção, é demonstrado o funcionamento do modelo de SCM praticado pela Siber do Brasil, seus clientes e seus fornecedores. Neste sistema, as ferramentas eletrônicas de TI são empregadas em consonância com a proposição do sistema híbrido de TOC-VMI-B2B aplicado ao SCM, apresentado no capítulo 3.

Neste caso, o CIS é o elemento central de convergência e processamento de todas as informações de demanda e estoques do sistema como um todo.

Integrado ao CIS, o modelo VMI se incumbe da integração entre a Siber do Brasil, seus clientes e seus fornecedores. Com esta solução, a Siber administra a produção e os estoques ao longo de toda a cadeia de suprimentos (pulmões), através de um portal na internet, utilizando um sistema B2B.

A Figura 31 apresenta, de forma ilustrativa, a operação do modelo e suas interfaces. 


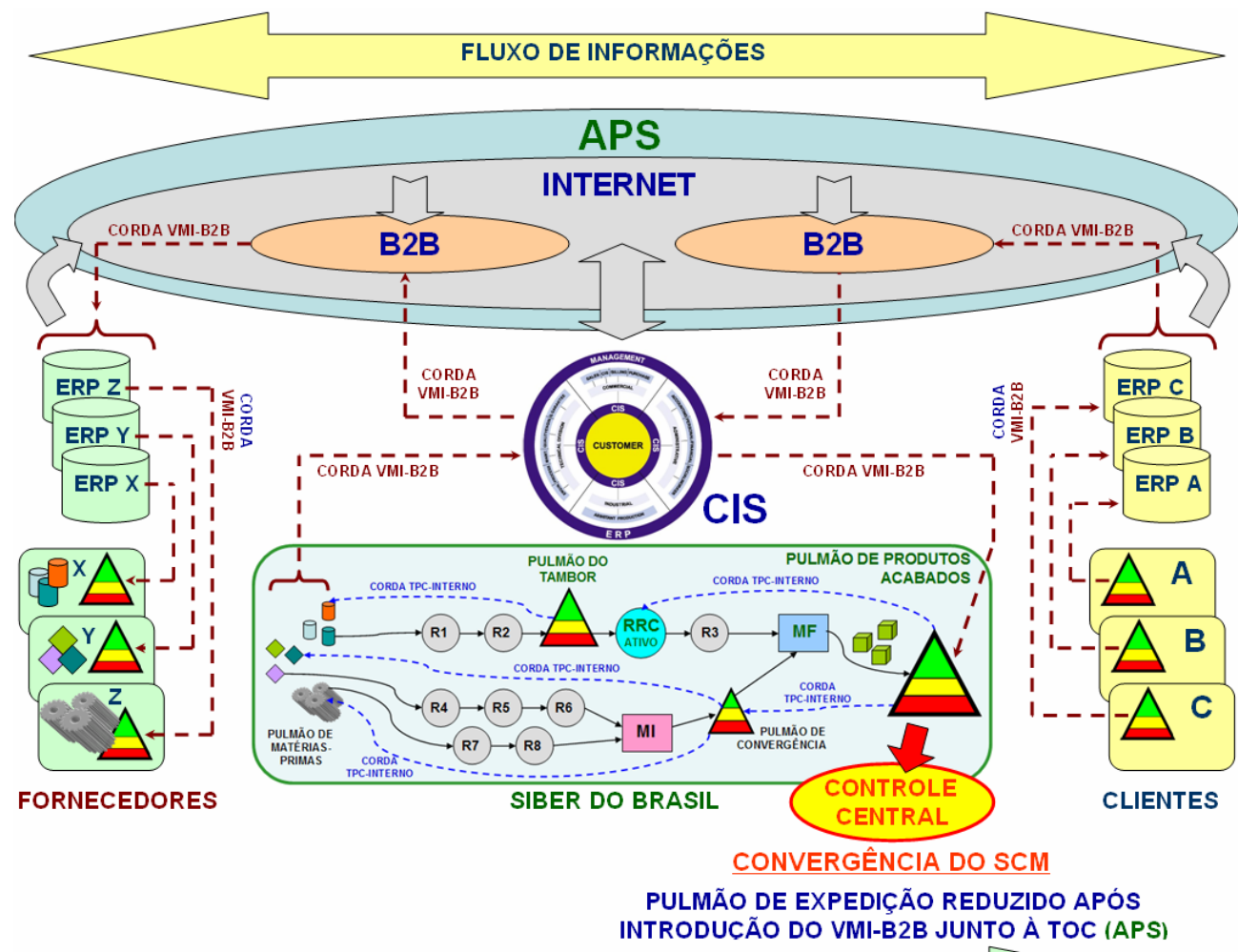

FLUXO DE MATERIAIS

Figura 31 - CIS na cadeia de suprimentos utilizando a TOC-VMI-B2B, propiciando ao modelo operar como um planejamento e programação avançados (advanced planning and scheduling - APS), realizando todo o compartilhamento de informações entre os ERPs dos fornecedores e clientes.

O processo desta cadeia de suprimentos é descrito a seguir, seguindo a lógica do sistema "puxado", em convergência com o modelo teórico de TOC-VMI-B2B apresentado no capítulo 3:

- $1^{\circ}$. - Os níveis dos estoques (pulmões) de matérias-primas dos clientes A, B e C da Siber do Brasil diminuem conforme a demanda diária de suas linhas de manufatura,

- $2^{\circ}$. - As cordas "VMI-B2B" garantem que os níveis reais de estoques de matérias-primas estejam devidamente registrados nos sistemas ERPs, exclusivos de cada cliente A, B e C; 
- $3^{\circ}$. - Através de um portal B2B na internet, as cordas "VMI-B2B" informam ao CIS, em tempo real, sobre a necessidade de reposição das matérias-primas consumidas pelos clientes A, B e C;

- $4^{\circ}$. - O CIS "dispara" então, através da corda "VMI-B2B", a necessidade de reposição aos clientes A, B e C, abastecendo-os a partir do estoque de produtos acabados da Siber (pulmão de expedição);

- $5^{\circ}$. - O consumo do pulmão de expedição sinaliza a sua necessidade de ser recomposto, "puxando" a fabricação interna da Siber, de acordo com a demanda dos clientes A, B e C;

- $6^{\circ}$. - O ritmo e o fluxo da fabricação e da movimentação de materiais internos são cadenciados através da programação TPCinterna, subordinados ao RRC "eleito" pela alta administração da Siber como o tambor do sistema;

- $7^{\circ}$. - As cordas "TPC-interno" comandam a entrada de insumos no sistema produtivo, diminuindo os estoques (pulmões) de matériasprimas da Siber conforme a demanda diária de sua fabricação interna, sinalizando ("puxando") ao CIS, através da corda "VMIB2B", as necessidades de recomposição destes pulmões de matériasprimas pelos fornecedores $\mathrm{X}, \mathrm{Y}$ e Z;

- $8^{\circ}$. - Através do mesmo portal B2B na internet, as cordas "VMIB2B" permitem ao CIS sincronizar os fornecedores X, Y e Z sobre a necessidade de reposição das matérias-primas consumidas pela fabricação interna da Siber, através de seus respectivos ERPs, em tempo real;

- $9^{\circ}$. - Dentro dos fornecedores X, Y e Z, as cordas "VMI-B2B" garantem que os níveis reais de seus estoques de materiais acabados, a serem expedidos para a Siber, estejam devidamente registrados nos seus respectivos sistemas ERPs, exclusivos de cada fornecedor X, Y e Z;

- $10^{\circ}$. - O consumo dos estoques de expedição internos dos fornecedores $\mathrm{X}, \mathrm{Y}$, e $\mathrm{Z}$ disparam, então, as suas necessidades de recomposição, acionando as suas respectivas linhas de fabricação interna, bem como os seus processos de suprimentos; 
- $11^{\circ}$. - O poder do CIS em centralizar, processar, demandar e comunicar, para todos os parceiros da cadeia, todas as informações pertinentes ao gerenciamento e tomadas de decisões, só é possível graças à sincronização integrada entre os ERPs dos clientes até os fornecedores, agindo como um sistema advanced planning and scheduling - APS, calculando e determinando, através do algoritmo da TOC, a capacidade de produção das empresas, a visualização e o controle global da disponibilidade de materiais, e o alinhamento de todo o processo com a demanda real do mercado (HUGOS, 2003).

Com a gestão dos estoques feita pela Siber por meio do VMI, e consequente integração das informações entre clientes, fornecedores e a empresa, ocorre uma significativa redução do efeito chicote, decorrente do excesso de segurança nas estimativas, ocasionados pela falta de visibilidade do planejamento.

Com conhecimento do plano final de vendas dos clientes, o VMI concede à Siber monitorar e impedir estoques em demasia, além de transportar este conceito para seus fornecedores, passando estes a administrarem seus próprios estoques (pulmões) com pleno conhecimento de toda a cadeia de vendas. Este modelo provoca redução em todos os níveis de estoques, com consequente redução dos custos logísticos e reflexo direto no custo final de venda.

Para superar as dificuldades encontradas pelo VMI para a gestão interna do planejamento da produção e desmembramento da árvore de produtos, este conta com a programação TPC interna vinculada ao nível de consumo do pulmão de produtos acabados da Siber do Brasil.

Após a identificação das restrições do sistema, o modelo TPC define um pulmão de tempo para proteção do RRC (recurso restritivo de capacidade, ou tambor de manufatura interna), e pulmões auxiliares nos pontos de convergência do sistema de manufatura (pulmões secundários ou pulmões de alimentação), utilizando-se da corda (corda "TPC-interno") para assegurar a captação correta de informações, possibilitando o sincronismo do sistema ao consumo do pulmão de produtos acabados, subordinando então a manufatura interna da Siber com a demanda do mercado.

Lembrando que, no sistema convencional proposto pela TOC, a corda aciona o início do processo (informação que dispara o sistema de forma a subordinar todas as atividades à restrição).

Transpondo-se da manufatura interna da Siber do Brasil para o SCM, no sistema CIS a corda passa a ser o próprio VMI (corda "VMI-B2B"), que irá 
sincronizar a produção da Siber do Brasil à produção de seus fornecedores, com base nas vendas de seus clientes. O referencial fundamental para o planejamento central de todo o SCM (o ponto de convergência sensível de todo o sistema) passa a ser o pulmão de expedição da Siber do Brasil (destaque da Figura 31).

Este controle da demanda de mercado através do pulmão de expedição da Siber do Brasil, convergindo e cadenciando, tanto os seus clientes e fornecedores, quanto a programação interna da fábrica, vem então, de certa forma, ao encontro da aplicação do TPC-Simplificado no SCM da Siber.

Porém, independente da possibilidade ou não de haver um RRC ativo, é opção da Siber do Brasil, em qualquer circunstância, continuar subordinando a programação interna da fábrica com base no TPC tradicional, onde o tambor sempre será o recurso com menor capacidade de produção, independente se seu desempenho é superior ou inferior à demanda de mercado.

A justificativa para esta escolha se embasa no fato de que, para a alta administração da Siber, o CIS é programado e dimensionado para suportar e absorver este cenário e, ao mesmo tempo, manter o compartilhamento da gestão entre os gerentes, planejadores, programadores, diretores e demais funcionários das plantas de manufatura da companhia (cultura TOC-VMI-B2B).

Esta postura é oposta ao recomendado por Schragenheim e Dettmer (2000b), conforme discorrido no capítulo 3. Porém, as características dos produtos da Siber, seu regime de mercado, sua infra-estrutura, a maturidade de gestão dos colaboradores, o alinhamento entre clientes e fornecedores, e, por último, a combinação do VMI-B2B suportado pelo algoritmo do CIS, fazem da companhia uma eficaz administradora do SCM em âmbito global, propiciando assim a manutenção contínua do TPC tradicional internamente, independente da demanda.

Este sistema contribui para a redução dos estoques de produtos acabados, localizados nas empresas, para atender toda a demanda dos clientes finais (dimensionados segundo o emprego da TOC ao SCM). Isto se promove através da aplicação do módulo da TOC desenvolvido para a manufatura (programação TPC interna), integrado ao VMI (cuja função equivale à corda VMI-B2B) através do CIS, desta forma, contribuindo ainda mais para a redução e o controle dos estoques ao longo da cadeia de suprimentos.

Conforme exposto anteriormente, sendo a interface entre a Siber e seus clientes e fornecedores realizada através de um portal B2B na internet, o sistema "puxado" permite que qualquer possível replanejamento de produção de qualquer um dos clientes A, B e C, dispare automaticamente o sistema TPC, iniciando o processo a partir do consumo dos pulmões dos próprios clientes, os quais, através 
da corda VMI-B2B, informam todos os parceiros predecessores sobre as mudanças, incluindo a própria Siber, seus recursos internos e seus fornecedores $\mathrm{X}, \mathrm{Y}$ e Z .

Estes recebem imediatamente um e-mail informando que houve uma alteração, não somente na progressão de consumo dos pulmões dos clientes $\mathrm{A}, \mathrm{B}$ e $\mathrm{C}$, mas também em seus respectivos planejamentos, convidando então todos os fornecedores a acessarem o portal para tomar conhecimento das alterações, que já estão disponíveis através da Corda/VMI.

Caso algum dos fornecedores $\mathrm{X}, \mathrm{Y}$ e $\mathrm{Z}$ não acesse o portal em 2 horas, $\mathrm{o}$ sistema passa a enviar e-mails a cada 2 horas, incluindo um e-mail para o Departamento de Logística da Siber do Brasil S.A., para informar um possível problema de comunicação com este fornecedor.

Desde que foi implementado, o sistema demonstrou muita eficiência na gestão da cadeia de suprimentos da Siber do Brasil, com redução acentuada dos estoques, aumento da velocidade de resposta aos clientes e consequente redução dos custos.

Porém, para o sucesso deste programa, o sistema necessita de um ambiente de total confiança entre clientes e fornecedores.

\subsection{RESULTADOS E CONCLUSÕES}

Sumarizando a aplicação real aqui exposta, o desempenho da cadeia de suprimentos da Siber do Brasil pode ser separado em três fases distintas:

- A primeira, com a utilização de um sistema tradicional de ERP baseado no MRP-II (Manufacturing Resource Planning) para apoiar as informações gerenciais;

- A segunda, com o uso parcial do sitema CIS, porém utilizando-se o módulo da programação TPC em sua logística interna de manufatura, ainda sem a implementação do modelo logístico completo, o qual inclui as soluções VMI e B2B;

- E finalmente, a última e atual fase, com a aplicação do modelo híbrido TOC-VMI-B2B, integrando a empresa com toda a cadeia de suprimentos, convergindo a Siber, seus clientes e fornecedores a operarem sincronizadamente com as necessidades do mercado. 
A implementação do CIS certamente foi um ponto de ruptura que propiciou a transformação da cultura da empresa. Este novo sistema, com filosofia de gerenciamento focada no cliente, permitiu expor para os gerentes informações relevantes acerca do real comportamento da cadeia de suprimentos. Os resultados obtidos neste período foram significativos quando comparados com os períodos anteriores.

De fato, a implementação do CIS, focada principalmente nas necessidades dos clientes, produziu grandes melhorias nos processos produtivos, os quais começaram a operar por células de manufatura, com operadores multifuncionais, resultando em melhores indicadores de qualidade. Todavia, os estoques continuavam altos, e os acionistas insatisfeitos com os resultados.

Um estudo adicional indicou que, com investimentos relativamente baixos, o CIS poderia incorporar um novo módulo logístico baseado na TOC-VMI-B2B, tendo isto gerado grande expectativa com respeito às melhorias no desempenho da cadeia de suprimentos.

O módulo foi implementado e, após isto, mensalmente a direção da empresa promove uma reunião com todas as áreas envolvidas para discutir e analisar os resultados. O principal objetivo é evitar a depreciação dos indicadores de desempenho alcançados e, ao mesmo tempo, assegurar que as necessidades dos clientes finais sejam atendidas.

Em resumo, os resultados alcançados nos últimos períodos foram expressivamente melhores quando comparados com as fases anteriores, e mais ainda, melhores do que as médias de mercado. O novo sistema de gerenciamento, com o suporte do CIS, demonstrou ser robusto e flexível para evoluções futuras. A Tabela 2 apresenta um comparativo antes e depois da implementação. 
Tabela 2 - Indicadores da Siber do Brasil antes e depois da implementação do sistema TOC-VMI-B2B.

\begin{tabular}{|c|c|c|}
\hline Indicadores & $\begin{array}{c}\text { ANTES DO SISTEMA HÍBRIDO } \\
\text { DE TOC-VMI-B2B AO SCM }\end{array}$ & $\begin{array}{l}\text { APÓS O SISTEMA HÍBRIDO } \\
\text { DE TOC-VMI-B2B AO SCM }\end{array}$ \\
\hline $\begin{array}{l}\text { Nível de inventário interno, incluindo estoques } \\
\text { e work in process }\end{array}$ & $\begin{array}{l}4 \text { meses de produção, } \\
\text { porém com itens faltantes }\end{array}$ & Giro de estoque: 8 a 10 vezes \\
\hline $\begin{array}{l}\text { Nível de estoque de produto acabado nos } \\
\text { fornecedores }\end{array}$ & 6 a 8 meses de produção & $\begin{array}{c}3,5 \text { dias } \\
\text { (produção para a semana) }\end{array}$ \\
\hline $\begin{array}{l}\text { Nível de estoques de produtos acabados nos } \\
\text { clientes }\end{array}$ & $\begin{array}{l}\text { Em geral, } 2 \text { semanas a } 1 \text { mês, } \\
\text { porém alguns itens zeravam } \\
\text { devido aos atrasos provocados }\end{array}$ & 3 dias a 2 semanas \\
\hline $\begin{array}{l}\text { Responsividade: performance de atendimento } \\
\text { às necessidades do mercado (volume, lead time } \\
\text { e prazo) }\end{array}$ & $\begin{array}{l}\text { Em geral após } 2 \text { semanas, } \\
\text { porém havia muitos delays, } \\
\text { chegando até mais de } 1 \text { mês }\end{array}$ & $\begin{array}{l}4 \text { horas a partir da } \\
\text { colocação da } P O \text { mensal, } \\
\text { em regime de fluxo contínuo } \\
\text { ao longo do mês }\end{array}$ \\
\hline Custos de manufatura & $80 \%$ do Faturamento & $2 \%$ a $34 \%$ do Lucro Bruto \\
\hline Custos logísticos & $3,2 \%$ do Faturamento & $\begin{array}{c}1,2 \% \text { do Faturamento } \\
\text { (acabaram os embarques } \\
\text { emergenciais) }\end{array}$ \\
\hline Lucro líquido & $\begin{array}{l}-50 \% \text { do Faturamento } \\
-7 \% \text { do faturamento } \\
\text { (após a TOC) }\end{array}$ & $8 \%$ a $10 \%$ do Faturamento \\
\hline
\end{tabular}

A Siber do Brasil S.A., assim como muitas outras empresas em seu segmento industrial, precisou redirecionar seus processos administrativos, rompendo com os paradigmas existentes e, ao mesmo tempo, implementar novas filosofias de gerenciamento que tornaram possível um redirecionamento das metas da empresa em direção aos lucros e aos objetivos estratégicos. 
